\title{
Tsunamis: Seismological and Disaster Prevention Studies
}

\author{
Kenji Satake $^{1, *}$ and Fumihiko Imamura ${ }^{2}$ \\ ${ }^{1}$ Seismotectonic Research Section, Geological Survey of Japan, \\ Tsukuba 305, Japan \\ ${ }^{2}$ Disaster Control Research Center, Faculty of Engineering, \\ Tohoku University, Aoba-ku, Sendai 980, Japan
}

\begin{abstract}
Japanese tsunami studies in the 1980's are reviewed. Because of the multi-disciplinary nature of the phenomenon, tsunamis are studied by researchers from various fields, including seismologists, geologists, oceanographers and coastal engineers. The tsunami from the 1983 Japan Sea earthquake caused 100 fatalities, and stimulated tsunami research, cooperation of workers from various fields for comprehensive work, and development of a quick tsunami warning system. Recent research developments include descriptive studies of the size and location of past tsunamis, tsunami observational systems, the generation and propagation of tsunamis, coastal effects, and a tsunami warning system.
\end{abstract}

\section{Introduction}

Most large shallow earthquakes around Japan occur beneath the ocean and generate sea waves, or tsunamis, as well as seismic waves. Tsunami, meaning harbor-wave, is one of a small number of Japanese words that have become international. Because of the multi-disciplinary nature of the phenomenon, tsunamis have been studied by geologists, seismologists, oceanographers and coastal engineers. The operation of tsunami warning systems requires knowledge about all of the above fields and rapid communication involving international cooperation.

The study of tsunamis has a long history in Japan. In the past, theoretical studies of tsunami generation and propagation were emphasized (e.g., Takahashi, 1942; Kajiura, 1963). In recent years, more practical and comprehensive studies from generation to coastal run-up have been developed. One of the catalysts for such comprehensive and cooperative work was the 1983 Japan Sea earthquake of May 26, 1983 (M 7.7), which generated a large tsunami that caused 100 fatalities. This was the largest tsunami disaster in Japan since 1960, when the tsunami from the Chilean earthquake propagated across the Pacific Ocean and killed about 140 people.

In this paper, we review recent developments in the broad area of tsunami research

Received April 30, 1992; Accepted April 21, 1994

* To whom correspondence should be addressed. 
in Japan, and illustrate how cooperation has arisen among researchers from various fields. We also examine how the 1983 Japan Sea earthquake tsunami stimulated further developments in tsunami research. After this paper was submitted in early 1992, several damaging tsunamis have occurred in the world, including that from the 1993 Southwest Hokkaido earthquake (M7.8). Various research on these tsunamis is still being conducted and the coverage on these studies are incomplete.

\section{Descriptive Studies of Tsunamis}

\subsection{Location and size of tsunamis}

The tsunami source area can be estimated in a manner similar to that used to locate earthquakes using $S-P$ time, except that the time difference between tsunami arrival time and the origin time is used. Because of the very slow propagation velocity of tsunamis compared to that of seismic waves, a finite source area is usually estimated. The wavefront, or ray path, can be drawn from each station backwards to the source area. Such diagrams are called inverse refraction diagrams and are extensively used in Japan (Miyabe, 1934; Hatori, 1969; Abe, 1973). Figure 1 shows an example for the 1968 Tokachi-oki earthquake. Wavefronts corresponding to travel times for each station are shown as arcs in the center panel. The location of each station is shown in the left panel with numbers. The tsunami source area estimated in this way roughly corresponds to the aftershock area as shown in the left panel.

The size of tsunamis has been described by magnitude scales. The one longest in use is the Imamura-Iida scale, $m$ (Hatori, 1979, 1986a). It starts at -1 and is roughly equal to $\log _{2} H$, where $H$ is the maximum tsunami height. The definition of the height is ambiguous; it can be run-up height or amplitude on tide-gauge records. This scale is especially convenient for old tsunamis for which no instrumental records exist.
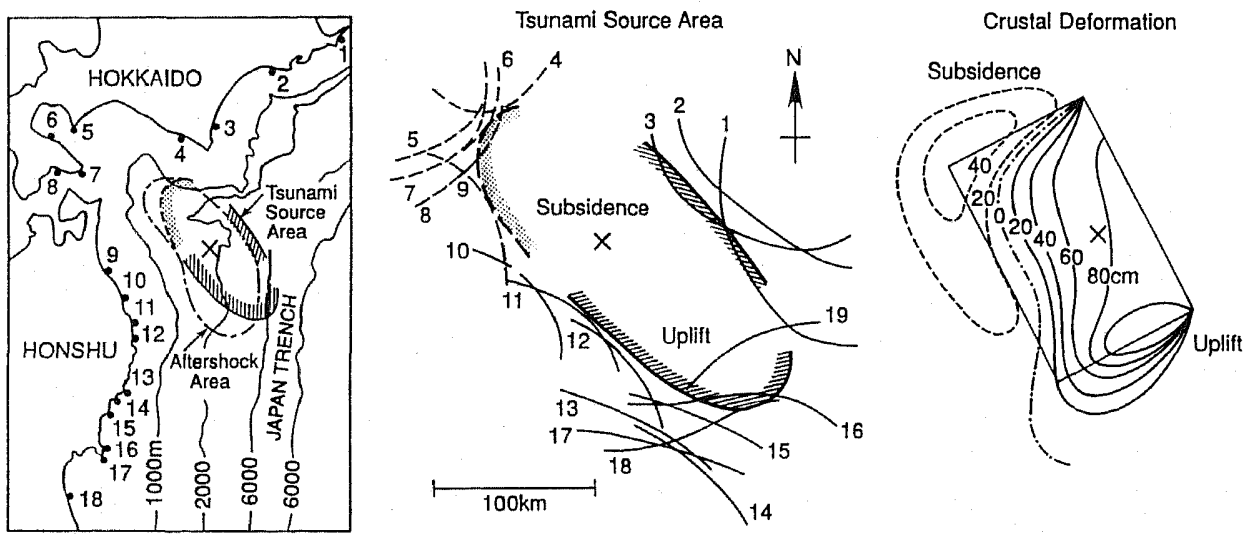

Fig. 1. The tsunami source area (center panel) and crustal deformation pattern (right panel) for the 1968 Tokachi-oki earthquake. In the center panel, the numbers beside each travel-time arc indicate the tide gauge station shown in the left panel. Solid and dashed arcs indicate positive and negative first arrivals, respectively. Modified from Abe (1973). 
Recently another magnitude scale $M_{\mathrm{t}}$, called tsunami magnitude, has been defined and assigned for many earthquakes by Abe (Abe, 1979, 1981, 1989 b). The definition for a trans-Pacific tsunami is:

$$
M_{\mathrm{t}}=\log H+C+9.1
$$

and for a regional $(100 \mathrm{~km}<\Delta<3,500 \mathrm{~km})$ tsunami in the northwestern Pacific ocean is:

$$
M_{\mathrm{t}}=\log H+\log \Delta+5.8,
$$

where $H$ is a maximum amplitude on tide gauges in $\mathrm{m}, C$ is a distance factor depending on a combination of the source and the observation points, and $\Delta$ is the actual distance in $\mathrm{km}$. The above formulas were calibrated with the moment magnitude scale, $M_{\mathrm{w}}$, of earthquakes. The 1968 Tokachi-oki earthquake tsunami (Fig. 1) was $m=2$ and $M_{\mathrm{t}}=8.2$. The 1983 Japan Sea earthquake tsunami was $m=3$ and $M_{\mathfrak{t}}=8.1$, and the $1993 \mathrm{SW}$ Hokkaido earthquake tsunami was $m=3$ and $M_{\mathrm{t}}=8.1$.

\subsection{Field surveys to document run-up heights}

After damaging tsunamis occurred, field surveys are usually carried out to measure run-up heights and to collect eyewitness accounts. Preliminary survey reports for the recent tsunamis were made by Satake et al. (1993) for the 1992 Nicaragua tsunamis, by Yeh et al. (1993) for the 1992 Indonesia tsunamis, and by the Hokkaido Tsunami Survey Group (1993) for the 1993 SW Hokkaido tsunamis.

For historical tsunamis, the run-up heights can be estimated from historical literature such as official diaries. Such literature studies have provided much important information about long-term seismicity and recurrence intervals of earthquakes (Usami, 1988) and tsunamis (Hatori, 1977; Tsuji, 1983). Tsuji (1987) estimated the damage distribution for historical tsunamis on the basis of necrologies archived at temples. Historical documents usually give tsunami height from local reference points; complementary field surveys are sometimes necessary to measure the run-up heights from sea level (Hatori et al., 1983; Shuto et al., 1987).

Geological methods also have become popular in studying old earthquakes. Minoura and Nakaya (1991) drilled boreholes to detect tsunami deposits. Sedimentological and geochemical analyses have made it possible to estimate dates and run-up heights of prehistoric tsunamis and also the recurrence intervals and sizes of large earthquakes. For example, the recurrence interval of tsunamis that arrive at Sendai, northeastern Japan, is estimated at about 800 years. Investigation of archaeological relics, whether buried by running water or not, also helps to document tsunami run-up heights for past tsunamis (Abe et al., 1990). Kato and Kimura (1983) estimated the age of a boulder in Ishigaki Island, presumably transported by a tsunami in 1771, and claimed it to be the highest tsunami record in Japan.

\subsection{Tsunami catalog}

The location, size, run-up heights and damages of past tsunamis in and around Japan were compiled as a catalog by Watanabe (1985). This catalog contains 177 tsunamis that occurred between 684 and 1984 near Japan, and 40 trans-Pacific tsunamis that were observed in Japan with descriptions of tsunami travel times, run-up heights,

Vol. 43, No. 3, 1995 
damage, and earthquake parameters including intensity distributions.

\subsection{Tsunami probability}

Using the tsunami run-up heights from past tsunamis in the last 400 years, Aida (1988) estimated cumulative tsunami energy for each $20 \mathrm{~km}$ interval of the Japanese coast. Rikitake and Aida (1988) further estimated tsunami hazard probabilities for the period between 2000 and 2010 . They showed that the probability of a tsunami exceeding $5 \mathrm{~m}$ is as high as $41 \%$ in some parts of central Japan.

\section{Tsunami Observation System}

\subsection{Tide gauge systems}

Tsunamis are recorded on tide gauges. About 500 tide gauge stations are currently in operation in Japan for the purpose of monitoring ocean tides (GSI, 1989). Tsunami waveforms as old as those from the 1896 Sanriku earthquake have been recorded on these tide gauges.

Figure 2 (upper left) shows the typical structure of a Japanese tide gauge. The gauge is set in a well which is connected to the outer sea by an intake pipe. Because of the severe winter weather in northern Japan, particularly on the Japan Sea coast, some stations have mechanisms to filter out shorter-period components such as surf or ocean beat. Because the period of tsunami waves is also shorter than that of ocean tides, tsunamis are also affected by the tide gauge structure. For example, the visually observed tsunami height from the 1983 Japan Sea earthquake was reported to be more than twice that measured on tide-gauge records at some nearby stations.

After the 1983 tsunami, systematic studies including theoretical computations and

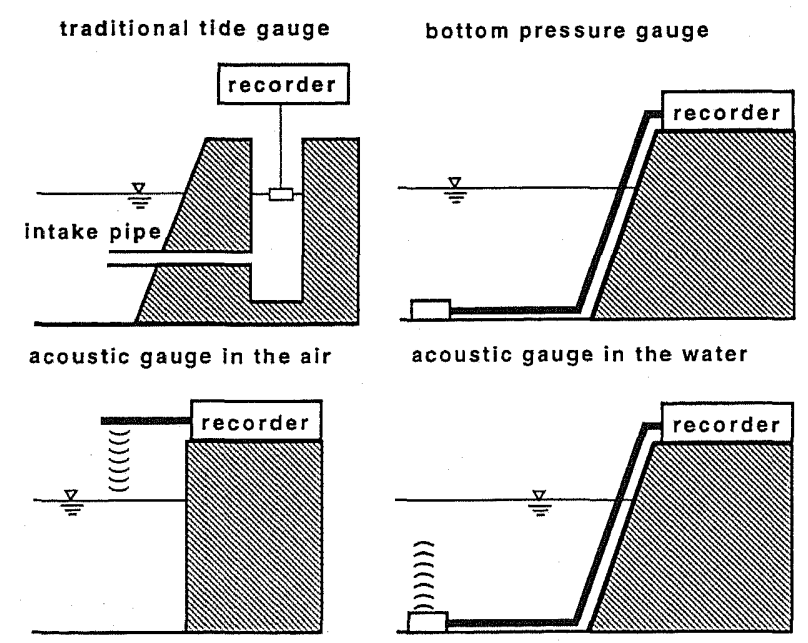

Fig. 2. Schematic pictures of tsunami recording systems. The upper left shows a traditional tide gauge. The newly developed tsunami gauges include the ocean bottom tsunami gauge (upper right) and acoustic gauges (lower two). 
in situ measurements of tide gauge responses were carried out (Murakami, 1983; Okada, 1985; Satake et al., 1988). The results showed that at some stations the response was very slow because of the intake pipe. If the tsunami period is shorter than the response time of the tide-gauge system, the tide-gauge system cannot follow the actual sea water movement of the tsunami, causing the recorded waves to be distorted. If the response of the system is known, tide-gauge records can be corrected to estimate the real tsunami waveforms.

\subsection{Tsunami gauges}

In recent years, efforts have been made to develop and deploy instruments specially designed to record tsunamis (e.g., Aida et al., 1981; Tada et al., 1991). These are called tsunami gauges or wave gauges. New types of tsunami gauge include pressure gauge and acoustic gauge (Fig. 2). The pressure gauges are set on the ocean bottom. The acoustic gauges are set either above the water level, measuring the travel time of acoustic wave in the air, or on the sea bottom and measures the travel time in the water. These are more suitable to measure the shorter period waves than conventional tide gauges. Wave gauges, however, do not continuously measure water heights. For tsunami observation, it is necessary and important to make continuous measurements. Ultrasonic wave gauges were installed in Kesennuma bay by the city office for the purpose of tsunami warning systems (Sato et al., 1992). These gauges recorded the 1992 Nicaragua tsunamis across the Pacific ocean, tide gauge in Japan could not detect such a small tsunami signal. Most of these gauges are set in shallow (up to $100 \mathrm{~m}$ ) water.

The Japan Meteorological Agency (JMA) has been operating two ocean bottom cables that telemeter seismic and tsunami data in real time from permanent ocean bottom seismographs and pressure gauge sensors (MRI, 1980). Four pressure gauges are installed over $100 \mathrm{~km}$ offshore Honshu, where the ocean depth is more than $2,000 \mathrm{~m}$ (Fig. 3). This system provides valuable data for tsunami research (Okada, 1991; Satake

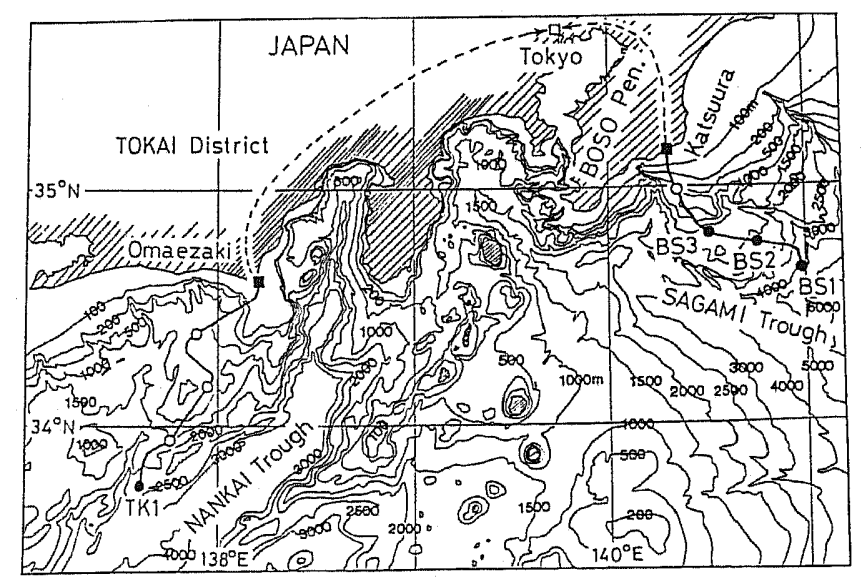

Fig. 3. The location of permanent ocean bottom seismograph system. Seismographs are laid at the open and closed circles and tsunami gauges are installed at the closes ones. From Okada (1991). 
et al., 1992; Imamura and Shuto, 1993), and is also used as a part of a tsunami warning system, as we discuss below.

\section{Tsunami Generation}

\subsection{Earthquake fault model}

Tsunamis are generated from disturbance of the ocean surface or bottom. Among various geological phenomena that cause tsunamis, earthquake tsunamis are the most frequent and well studied. Abe (1973) showed that the pattern of water surface disturbance, either uplift or subsidence, in the tsunami source area for the 1968 Tokachi-oki earthquake was consistent with the crustal deformation pattern estimated from seismological analyses (Fig. 1).

Because of the long wavelength of crustal deformation compared to the water depth, the water surface disturbance can be assumed to be the same as the crustal deformation on the ocean bottom (Kajiura, 1963). Kajiura (1970) examined the efficiency of tsunami generation in terms of energy exchange and showed that source motion can be considered abrupt if the duration is less then several minutes. Kajiura (1981) also examined the relationship between fault parameters and tsunami energy.

Tsunami generation and propagation from fault motions have been calculated analytically (Yamashita and Sato, 1974), using normal mode theory (Ward, 1980, 1981, 1982; Comer, 1984; Okal, 1988) or numerically (Aida, 1974). Aida (e.g., Aida, 1978) made numerical computations for many earthquakes. For each event, he computed tsunami waveforms for several fault models and compared them with the observed tsunami waveforms. Aida (1977 b) further used an empirical relationship between the computed tsunami wave height at $200 \mathrm{~m}$ depth and the average inundation heights (the latter is about two to three times larger than the former) to estimate the fault parameters of old earthquakes for which no tsunami waveforms are available.

\subsection{Inversion for heterogeneous fault motion}

Since tsunami waveforms vary with the fault parameters, earthquake fault parameters can be estimated from the observed tsunami waveforms. Aida (1972) tried to estimate the initial water disturbance from the observed tsunamis waveforms. In the 1980's, seismologists found that fault motion of large earthquakes is not uniform but has heterogeneities described as asperities or barriers. Satake (1989) inverted tsunami waveforms in the same way as seismic waves to estimate the heterogeneous slip distribution on the fault for the 1968 Tokachi-oki and 1983 Japan Sea earthquakes (Fig. 4). Figure 5 shows a comparison of observed tsunami waveforms with the computed ones for a heterogeneous slip distribution for the 1983 Japan Sea earthquake. Satake (1993) further examined the slip distribution for the 1944 Tonankai and 1946 Nankaido earthquakes. For such old earthquakes, tsunami data provide better information about the source motion than seismic waves.

\subsection{Tsunami earthquakes}

Some earthquakes, e.g., the 1896 Sanriku or 1946 Aleutian earthquakes, caused abnormally larger tsunamis than expected from seismic waves. Kanamori (1972) named 


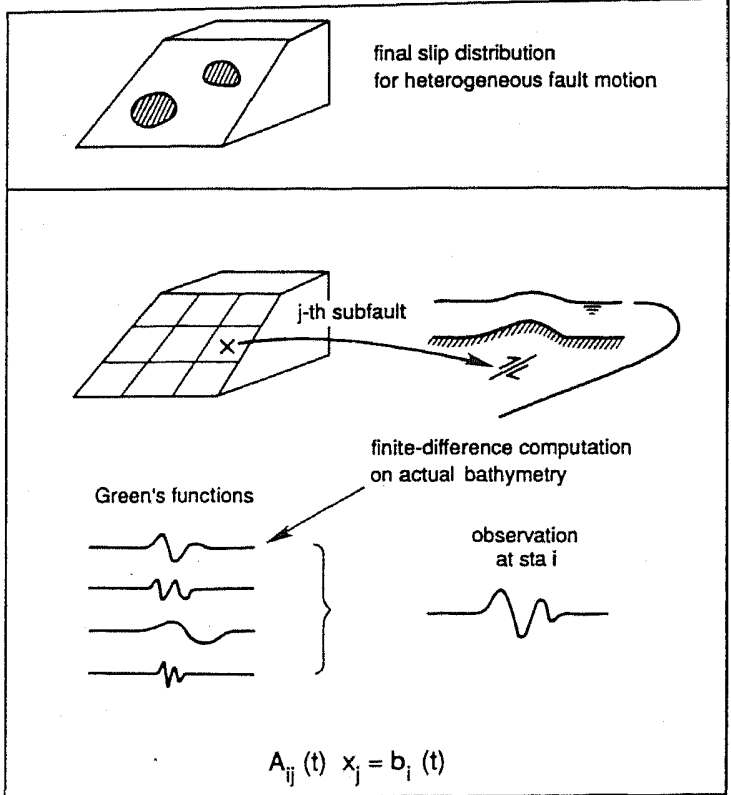

Fig. 4. Schematic illustration showing the inversion of tsunami waveforms to estimate the slip distribution on an earthquake fault.

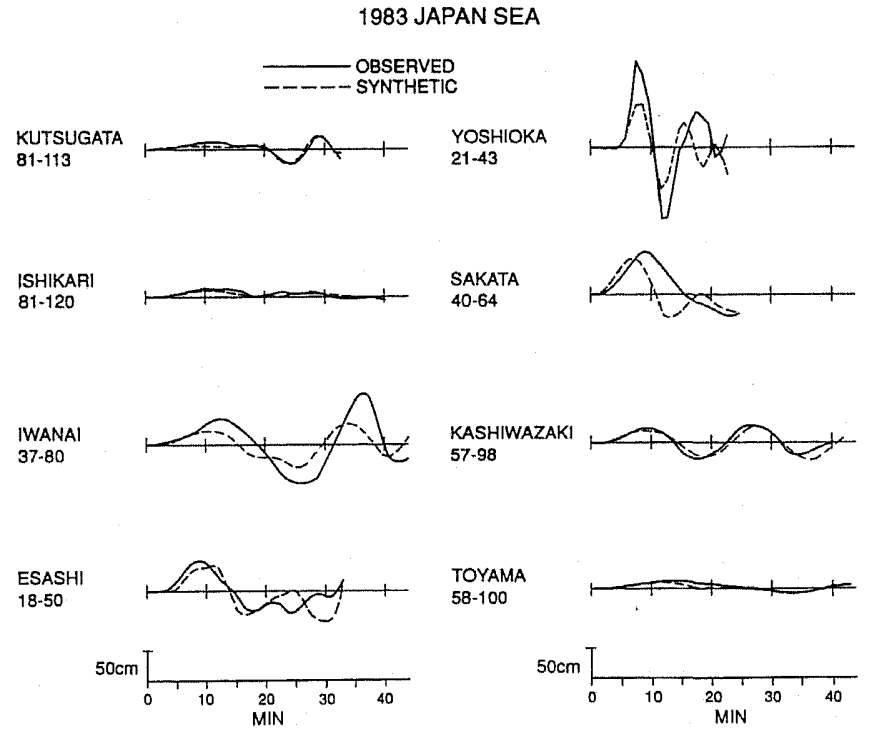

Fig. 5. Observed tide-gauge records from the 1983 Japan Sea earthquake tsunami and the computed one from the source model obtained by the inversion. From Satake (1989).

Vol. 43, No. 3, 1995 
such earthquakes "tsunami earthquakes." Abe (1989a, b) quantitatively defined a tsunami earthquake an event whose tsunami magnitude $\left(M_{\mathrm{t}}\right)$ exceeds the surface wave magnitude $\left(M_{\mathrm{s}}\right)$ by more than 0.5 . Kanamori (1972) proposed that an unusually slow source process would excite relatively large tsunamis compared to seismic waves. Other models have been also proposed; Fukao (1979) proposed that a high-angle fault in the shallow sediment layer caused larger tsunami than seismic waves for the 1975 Kuril earthquake. Satake and Kanamori (1991) showed that the unusually large tsunami from the 1984 Torishima earthquake was due to abnormal tsunami propagation along the ridge system as well as an unusual source mechanism of the earthquake, probably the intrusion of magma into sediments. The 1992 Nicaragua earthquake was also identified as a tsunami earthquake (Ide et al., 1993; Imamura et al., 1993; Kanamori and Kikuchi, 1993; Satake et al., 1993).

\subsection{Tsunamis from other causes}

Volcanic eruptions also generate tsunamis. Although they are less frequent than earthquake tsunamis, volcanic tsunamis have caused tremendous damage. A few analyses or model calculations have been done for tsunamis from volcanic origin. The eruption of Unzen in 1792 (which also erupted in 1990), caused a collapse of Mayuyama, which caused a huge tsunami and killed 15,000 people (Aida, 1975). The 1883 eruption of Krakatau, probably the largest eruption in the world in recent centuries, also caused a tsunami and claimed about 36,000 lives. The generation mechanism of this tsunami has been debated for the last decade (Yokoyama, 1981, 1987; Latter, 1981; Self and Rampino, 1982; Camus and Vincent, 1983; Francis, 1985). Recently, more numerical computations (Nishimura and Satake, 1993; Nomanbhoy and Satake, 1995; Kawamata et al., 1993) and hydraulic experiment (Togashi and Hirayama, 1993) have been made to model these volcanic tsunamis.

The 1741 tsunami generated near Oshima-Ohshima, between the 1983 Japan Sea and 1993 SW Hokkaido earthquakes was enigmatic; the tsunami damage was too extensive to be of volcanic origin (Aida, 1984) but there is no record of an earthquake in historical literature, in contrast to many records describing the volcanic eruption.

\section{Tsunami Propagation}

\subsection{Governing equation}

The wavelength of tsunamis is usually much longer than the water depth. Such a wave can be treated as a long-wave (also known as shallow water wave) in hydrodynamics. The most general equation for a long-wave is the Boussinesq equation. For one-dimensional case, it is given as

$$
M_{t}+g h \eta_{x}+g \eta \eta_{x}+\left(M^{2} /(h+\eta)\right)_{x}+g n^{2} M^{2} /(h+\eta)^{7 / 3}=h^{2} M_{x x t} / 3
$$

where $M$ is the water discharge (horizontal velocity integrated from bottom to the surface), $\eta$ is the water height above still water level, $h$ is the still water depth, $g$ is the gravitational acceleration, $n$ is Manning's roughness coefficient, and subscript shows temporal $(t)$ or spatial $(x)$ derivatives.

The term on the right hand side shows dispersion. Dispersion becomes important 
only when a tsunami propagates a long distance on a mild slope or in a river. The last term in the left hand side accounts for bottom friction, which is often expressed by Manning's roughness coefficient. The third and fourth terms are for non-linear motion of water. The non-linear and friction terms become important only for shallow water depth. For tsunami propagation in deep water, only the linear terms (the first two terms in the left hand side) need to be considered. In such a case, the equation becomes the linear long-wave equation whose velocity is given as $\sqrt{g h}$. Since the velocity depends on ocean depth, which is usually well known, tsunami propagation can be accurately computed. Satake (1988) applied ray-tracing to tsunamis and showed that the effect of bathymetry is very important for tsunami propagation.

\subsection{Numerical computation of tsunamis}

For tsunami propagation, the finite-difference method with a staggered leap-frog scheme has been most commonly used (Aida, 1969; Hwang et al., 1972). The crustal deformation pattern due to faulting can be used as the initial condition. At the boundary to the open sea, a radiation condition, in which tsunami waves go out of the computation region without changing their shape, is usually assumed. Different land boundary conditions are used depending on the purpose of the tsunami computation. When tsunami behavior in the deep ocean is examined, total reflections on a fixed coast can be assumed. When the evaluation of tsunami run-up is the main purpose of the computation, the ocean-land boundary cannot be fixed. Several methods have been proposed for a moving boundary (Aida, 1977a; Iwasaki and Mano, 1979) (Fig. 6).

The grid size for numerical computation is important for both stability and accuracy of computations. The grid size and computational time step must satisfy the stability condition,

$$
K=C \Delta t / \Delta x \leq 1.0
$$

where $K$ is the Courant number, $C$ is the wave velocity and $\Delta x$ and $\Delta t$ are the spatial grid size and time step.

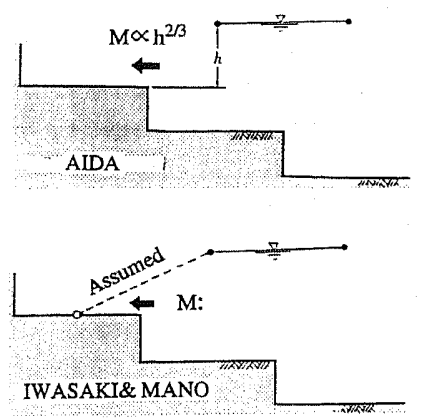

Fig. 6. Moving boundary conditions on the ocean-land boundary. That above is adopted by Aida (1977 a) with a weir-type formula and that below is by Iwasaki and Mano (1979) considering a relationship between velocity and water depth at the wave front. 
Sayama et al. (1988) examined the computational error on tsunami refraction due to the digitization of bathymetry. Imamura and Goto (1988) examined the truncation error associated with the finite-difference method and showed that a coarse grid size can cause numerical dispersion. For accurate computation of tsunamis, 20 to 30 grid points per wavelength are preferable (Shuto et al., 1986). For the tsunami run-up problem, Goto and Shuto (1983) examined the effects of grid size, wave period, slope and the moving boundary conditions on the computation.

For practical tsunami computation, the linear long-wave equation is used in the deeper ocean, with a larger grid size. In the near shore region, the non-linear equation must be used with a smaller grid size. Hence computations are usually made with variable grid size and governing equations.

\subsection{Numerical computation of trans-pacific tsunamis}

For tsunamis propagating a very long distance such as across the Pacific ocean, the effects of Earth's sphericity and rotation (Coriolis force) must be also included. Further, physical dispersion cannot be neglected (Kajiura, 1970). Imamura et al. (1990) showed that an appropriate choice of grid size can make the effects of numerical and physical dispersion equal. In other words, the finite difference computation for a linear long-wave can simulate the linear Boussinesq equation which includes a dispersion term. The choice of grid size is determined by the Imamura number, Im, defined as

$$
\operatorname{Im}=\Delta x \sqrt{1-K^{2}} / 2 h,
$$

where $h$ is the average water depth. The value of $I m$ must be about 1 . Figure 7 shows the effect of $I m$ for the propagation of the 1964 Alaskan earthquake tsunami.

\subsection{Edge wave and free oscillation of Japan Sea}

When a tsunami source is located on the continental shelf or a ridge system, the energy of a propagating tsunami is trapped on the shelf or ridge (Abe and Ishii, 1989; Satake et al., 1992). This is known as an edge wave in oceanography.

The tsunami from the 1983 Japan Sea earthquake was observed for as long as two days after the earthquake on the Japan Sea coast. This is due to the multiple reflection of tsunamis in the almost-closed Japan Sea (Hatori, 1986 b; Abe and Ishii, 1987; Abe, 1991). Satake and Shimazaki (1988 a, b) treated such tsunamis as a normal mode of

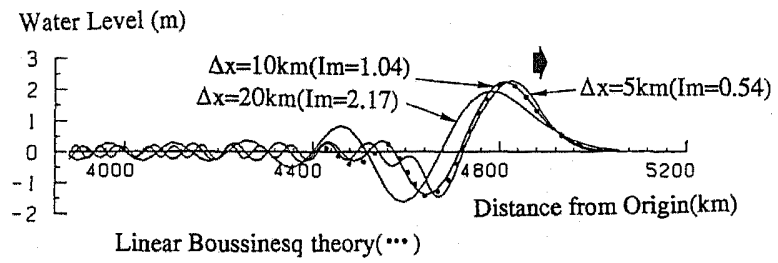

Fig. 7. Comparison of tsunami profiles computed for the 1964 Alaskan tsunami using the linear long-wave equation (solid lines) and the linear Boussinesq equation (dotted line). The profile from the linear long-wave equation with $I m=1.04$ agrees well with that from the linear Boussinesq equation. 

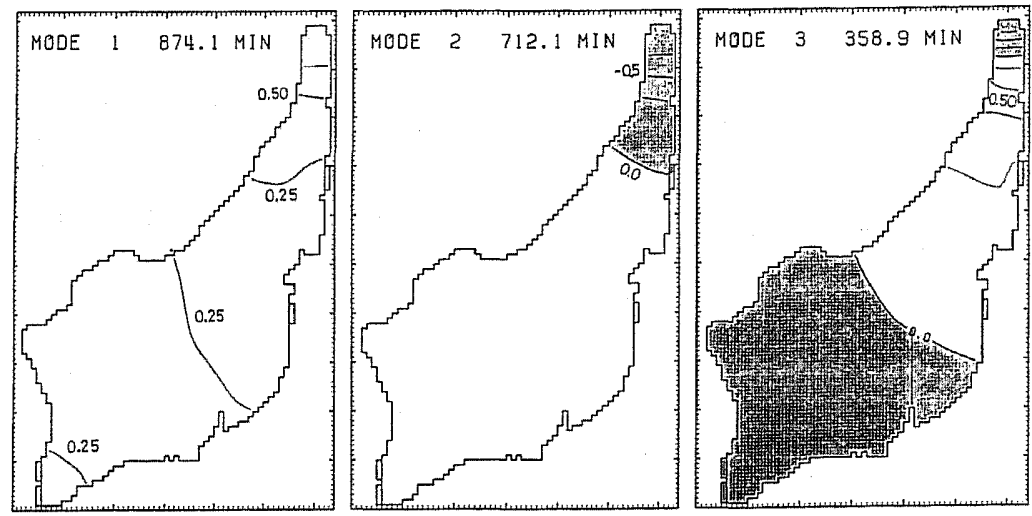

Fig. 8. Eigenvalues, or eigenperiods, and the corresponding eigenvectors, or water height patterns, for the three oscillation modes of the Japan Sea computed by Satake and Shimazaki (1988b).

the ocean basin. Figure 8 shows the periods and oscillation patterns for the three lowest fundamental modes of the Japan Sea. Satake and Shimazaki (1988 a, b) showed that a tsunami source in the deep ocean, such as the 1983 Japan Sea earthquake tsunami, excited free oscillations of the whole Japan Sea; whereas those occurring on the continental shelf, such as the 1964 Niigata earthquake tsunami, excited only regional oscillations.

\section{Coastal Effects}

\subsection{Flooding and damages to houses}

Takeda and Tsuji (1987) used LANDSAT data to estimate tsunami run-up heights and flooded areas for the 1983 Japan Sea earthquake tsunami by means of vegetation change. In order to make accurate numerical computations of tsunami flooding, the wave front must be determined and the friction law on the dry bed must be known. Fujima and Shuto (1990) conducted hydraulic experiments to estimate the friction law. Their result shows that Manning's law with a proper coefficient is sufficient for determining the maximum run-up. However, this law may not be applicable to the surge front of a tsunami.

When a tsunami runs over the land, the houses and other structures along the shoreline are damaged or washed away by the force of the tsunami. To evaluate such a wave impact force, the wave profile, pressure and particle velocity at the front must be accurately known. Matsutomi (1990) attempted to develop a procedure for predicting the maximum impulsive force due to floating timbers, and experimentally presented the apparent inertia coefficient and the impact duration time. Goto (1983) developed a numerical method to estimate the spread of timbers. Hatori (1984) found that damage to wooden houses is generally proportional to a drag force, defined as the product of the tsunami height and the square of water velocity. 


\subsection{Current due to tsunami}

The current due to tsunamis is not well known or recorded except for eyewitness accounts. A series of aerial photographs was taken at the time of the 1960 Chilean tsunami on Sanriku coast. From an analysis of these photographs, the current velocity on the water surface was estimated (Takahashi et al., 1993). The numerical computation of current requires finer grids than the standard tsunami computation for water height, since the direction and magnitude of the current are sensitive to the local topography. By comparison of experiments and numerical simulations, Tomizawa et al. (1990) showed that horizontal eddy viscosity must be included for accurate computation of tsunami current velocity.

Pearl culture was heavily damaged due to the current of the 1960 Chilean tsunami in Japan. Data on damage were collected in Matoya bay, Kii Peninsula. Sato (1960) investigated the degree of damage done to pearl culture rafts. A comparison of numerical computation to damage data showed that pearl culture rafts are safe as long as the maximum velocity is less than $1 \mathrm{~m} / \mathrm{s}$ (Nagano et al., 1991).

\subsection{Sand transport}

As we have seen before, geologists study tsunami deposits to get important information about past tsunamis and earthquakes (Abe et al., 1990; Dawson et al., 1991; Minoura and Nakaya, 1991). Possible disasters from future tsunamis, on the other hand, include the erosion near the foundation of a structure or deposition of sediments that may block the inflow mouth to an electric power plant. At this stage, it is difficult to compute sand transport due to tsunamis, because the evaluation of velocity, shear stress and transport formula have not been established. Future developments are expected because of the scientific and engineering applications.

Deformation of the sea bottom associated with the 1960 Chilean tsunami was observed in some harbors on the Sanriku coast. The change in the bottom profile due to the tsunami shows a mode similar to the annual change. The erosion in a river-harbor and a long and narrow harbor are remarkable whereas the erosion in a wide harbor is indistinct (Kawamura and Mogi, 1961). These data give valuable information which can be used to establish the sand transport simulation.

\subsection{Tsunami defense work}

Structures such as seawalls, tsunami breakwaters and tsunami gates provide a direct way to prevent tsunami hazards. The height of a sea wall is usually designed based on the highest water level from past tsunamis. Aida et al. (1988) examined by numerical experiments the behavior of tsunamis exceeding the design height. The result shows that when a tsunami has the same height as the sea wall, the water level near the wall becomes higher than the wall, because of the reflection. In this case, the water level at some places in the town becomes so high as to give rise to human and material damage in spite of the construction of the sea wall.

High seawalls are sometimes not welcomed because of inconveniences placed on the daily life of local residents. Alternatively, a tsunami-resistant building may be considered as a prevention structure. The tsunami force on this building and the reduction 
of tsunami effects on the houses behind it should be evaluated for the effective use of a tsunami-resisting building zone. A tsunami-control forest can also be expected to have a similar effect. Shuto (1987 a) estimated the effectiveness and limit of a tsunami-control forest in terms of the cumulative tree diameters and the density of undergrowth.

Recent growth in industrial activity has increased tsunami disaster potential. For instance, if an oil spill is accompanied by fire, the effect is devastating. Examples are found in Seward, Valdez and Whittier in Alaska (from the 1964 Alaskan earthquake), Niigata (from the 1964 Niigata earthquake) and Okushiri Island (from the 1993 SW Hokkaido earthquake). Numerical simulation can roughly estimate oil spread and burn area, and is applied to Miyako bay, the northern Sanriku coast (Goto, 1985; Shuto, 1987b).

\section{Tsunami Warning Systems}

Tsunami warning systems utilize the velocity difference between seismic and tsunami waves. The arrival time difference of these waves is obviously longer for larger distances. The Pacific-wide tsunami warning system is in operation through international cooperation. JMA is exchanging seismic and tide gauge data with foreign countries including the United States (Alaska and Hawaii), Micronesia (Palau Is.), Russia (Khabarovsk), South Korea and Hong Kong through satellite or telephone communications.

A tsunami warning system for local tsunamis is more challenging (Katsumata, 1987). The first arrival of the tsunami from the 1983 Japan Sea earthquake reached the coast $7 \mathrm{~min}$ after the earthquake and killed school children. The tsunami warning was issued $14 \mathrm{~min}$ after the origin time. Although this was still much shorter than the $20 \mathrm{~min}$, required by regulation, further developments have been made to issue tsunami warnings in shorter times. Currently, JMA has been equipped with the Earthquake Phenomena Observation System (EPOS; Fig. 9), which consists of super-mini computers, telecommunication links, and telemetry facilities connecting more than 60 seismic stations including two permanent ocean bottom seismographs (Yokota and Yamamoto, 1989). The EPOS automatically detects an event, picks $P$ and $S$ wave arrivals, estimates the hypocenter and magnitude, and issues a tsunami warning based on the criteria of location, magnitude and depth. Based on the judgment of the duty seismologist, the warning messages are distributed to the government, TV and radio stations. Because of this new system, the tsunami warning was issued in 5 min after the 1993 Southwest Hokkaido earthquake.

Zama and Yoshihara (1987) developed a simpler system, in which the location and magnitude are estimated from a three-component seismograph, and tsunami arrival times are then calculated from submarine earthquakes.

Seismological studies for more accurate and detailed tsunami warnings are still in progress. Assuming that tsunami and seismic magnitudes are equal and using the definition of tsunami magnitude, Abe (1989a) showed that tsunami heights can be predicted from an earthquake magnitude. Fukushima et al. (1989) showed the possibility of real-time moment tensor inversion using local data. Izutani and Hirasawa (1987) developed a simple method to estimate fault parameters from strong motion data. If

Vol. 43 , No. 3, 1995 


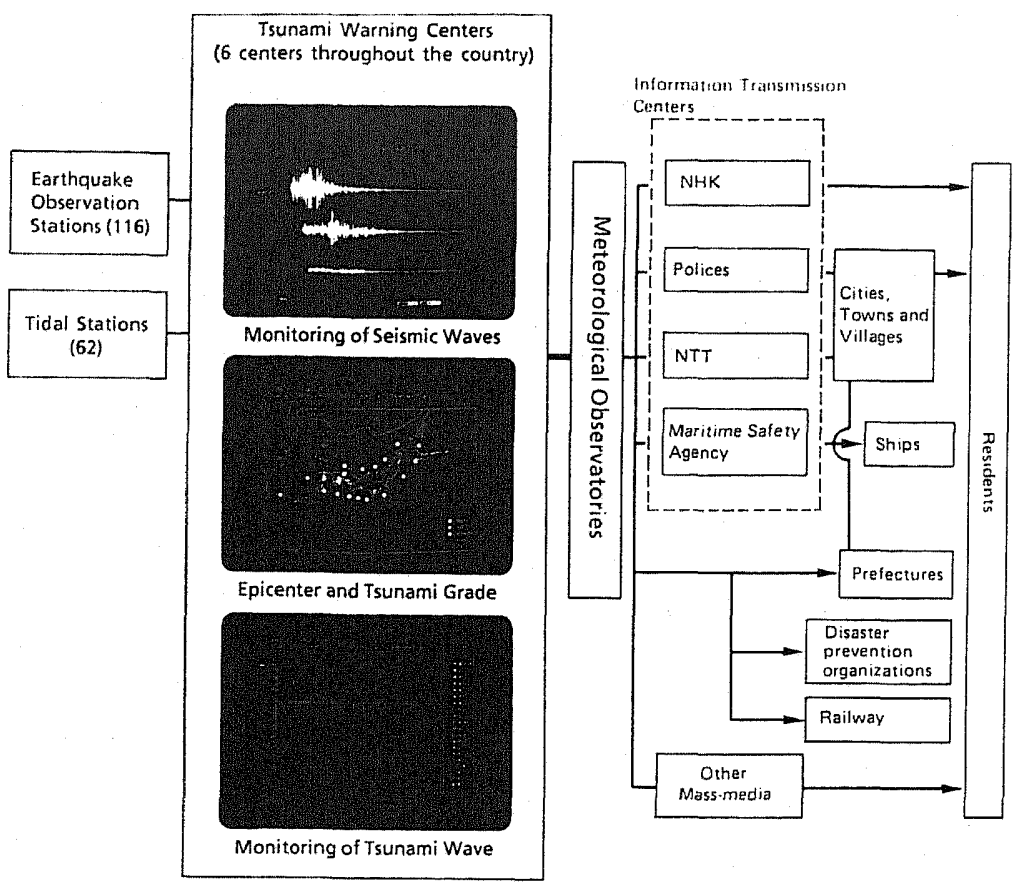

Fig. 9. Schematic illustration of current tsunami warning system of the Japan Meteorological Agency.

all of the fault parameters of earthquakes could be estimated in real time, the numerical computation of tsunamis could be made before the actual tsunami arrives at coastal regions, and more detailed warnings could be issued (Shuto et al., 1990). Iwasaki (1991) showed that measurements of the T-phase, not only on seismographs, but also reported from ships as sea-shocks, can be used to estimate the tsunami size.

\section{REFERENCES}

Abe, H., Y. Sugeno, and A. Chigama, Estimation of the height of the Sanriku Jogan 11 earthquake-tsunami (A.D. 869) in the Sendai plain, Zisin (J. Seismol. Soc. Jpn.), 43, 513-525, 1990.

Abe, Ka., Tsunami and mechanism of great earthquakes, Phys. Earth Planet. Inter., 7, 143-153, 1973.

Abe, Ka., Size of great earthquakes of 1873-1974 inferred from tsunami data, J. Geophys. Res., 84, 1561-1568, 1979.

Abe, Ka., Physical size of tsunamigenic earthquakes of the northwestern Pacific, Phys. Earth Planet. Inter., 27, 194-205, 1981.

Abe, Ka., Estimate of tsunami heights from magnitudes of earthquake and tsunami, Bull. Earthq. Res. Inst., Univ. Tokyo, 64, 51-69, 1989 a. 
Abe, Ka., Quantification of tsunamigenic earthquakes by the $M_{\mathrm{t}}$ scale, Tectonophysics, 166, 27-34, 1989 b.

Abe, Ku., Tsunami reflected waves from the coasts near the sources, J. Phys. Earth, 39, 477-488, 1991.

Abe, $\mathrm{Ku}$. and $\mathrm{H}$. Ishii, Distribution of maximum water levels due to the Japan Sea tsunami on May 26, 1983, J. Oceanogr. Soc. Jpn., 43, 169-182, 1987.

Abe, Ku. and $\mathrm{H}$. Ishii, Shelf tsunami and trench tsunami-one dimensional model, Sci. Tsunami Hazards, 7, 107-116, 1989.

Aida, I., Numerical experiments for the tsunami propagation-the 1964 Niigata tsunami and the 1968 Tokachi-oki tsunami, Bull. Earthq. Res. Inst., Univ. Tokyo, 47, 673-700, 1969.

Aida, I., Numerical estimation of a tsunami source, Zisin (J. Seismol. Soc. Jpn.), 25, 343-352, 1972.

Aida, I., Numerical computation of a tsunami based on a fault origin model of an earthquake, Zisin (J. Seismol. Soc. Jpn.), 27, 141-154, 1974.

Aida, I., Numerical experiments of the tsunami associated with the collapse of Mt. Mayuyama in 1792, Zisin (J. Seismol. Soc. Jpn.), 28, 449-460, 1975.

Aida, I., Numerical experiments for inundation of tsunamis-Susaki and Usa, in Kochi Prefecture, Bull. Earthq. Res. Inst., Univ. Tokyo, 52, 441-460, 1977 a.

Aida, I., Relation between tsunami inundation heights and water surface profiles on a $200 \mathrm{~m}$ depth contour, Zisin (J. Seismol. Soc. Jpn.), 30, 11-23, 1977 b.

Aida, I., Reliability of a tsunami source model derived from fault parameters, J. Phys. Earth, 26, 57-73, 1978.

Aida, I., An estimate of tsunamis generated by volcanic eruptions-the 1741 eruption of Oshima-Ohshima, Hokkaido-, Bull. Earthq. Res. Inst., Univ. Tokyo, 59, 519-531, 1984.

Aida, I., Cumulative tsunami energy on the Japanese coast as a measure of long-term tsunami hazard, Zisin (J. Seismol. Soc. Jpn.), 41, 573-581, 1988.

Aida, I., H. Tsubokawa, and M. Kawaguchi, Numerical experiments on behavior of tsunamis exceeding the design height of a sea wall-case studies for Matsuzaki, Shizuoka Prefecture and Taro, Iwate Prefecture, Zisin (J. Seismol. Soc. Jpn.), 41, 343-350, 1988.

Aida, I., D. Date, S. Sakashita, and M. Koyama, The new tsunami recorders (ERI-V) at the Enoshima and the Izu-Oshima tsunami observatories, Bull. Earthq. Res. Inst., Univ. Tokyo, 56, 571-585, 1981.

Camus, G. and P. M. Vincent, Discussion of a new hypothesis for the Krakatau volcanic eruption in 1883, J. Volcanol. Geotherm. Res., 19, 167-173, 1983.

Comer, R. P., The tsunami mode of a flat earth and its excitation by earthquake sources, Geophys. J. R. Astron. Soc., 77, 1-27, 1984.

Dawson, A. G., I. D. Foster, S. Shi, D. E. Smith, and D. Long, The identification of tsunami deposits in coastal sediment sequences, Sci. Tsunami Hazards, 9, 73-82, 1991.

Francis, P. W., The origin of the 1882 Krakatau tsunamis, J. Volcanol. Geotherm. Res., 25, 349-363, 1985.

Fujima, K. and N. Shuto, Formulation of friction laws for long waves on a smooth dry bed, Coastal Eng. Jpn., 33, 25-47, 1990.

Fukao, Y., Tsunami earthquakes and subduction processes near deep-sea trenches, J. Geophys. Res., 84, 2303-2314, 1979.

Fukushima, T., D. Suetsugu, I. Nakanishi, and I. Yamada, Moment tensor inversion for near earthquakes using long-period digital seismographs, J. Phys. Earth, 37, 1-29, 1989.

Geographical Survey Institute (GSI), Catalog of Tide Gauge Stations in Japan, Tsukuba, 127 pp., 1989.

Vol. 43, No. 3, 1995 
Goto, C., Numerical simulation of spread of floating timbers, Proc. 30th Conf. Coastal Eng., JSCE, 594-597, 1983.

Goto, C., A simulation model of oil spread due to tsunamis, Proc. Jpn. Soc. Civil Eng., 375, 217-223, 1985.

Goto, C. and N. Shuto, Numerical simulation of tsunami propagations and run-up, in Tsunamis: Their Science and Engineering, ed. K. Iida and T. Iwasaki, pp. 439-451, Terra Sci. Publ. Co., Tokyo, 1983.

Hatori, T., Dimensions and geographical distribution of tsunami sources near Japan, Bull. Earthq. Res. Inst., Univ. Tokyo, 47, 185-214, 1969.

Hatori, T., Historical Tsunamis (Rekishi Tsunami), Kaiyo Shuppan, Tokyo, 125 pp., 1977.

Hatori, T., Relation between tsunami magnitude and wave energy, Bull. Earthq. Res. Inst., Univ. Tokyo, 54, 531-541, 1979.

Hatori, T., On the damage to houses due to tsunamis, Bull. Earthq. Res. Inst., Univ. Tokyo, 59, 433-439, 1984.

Hatori, T., Classification of tsunami magnitude scale, Bull. Earthq. Res. Inst., Univ. Tokyo, 61, 503-515, 1986 a.

Hatori, T., Reflection waves from the continental coast for the 1983 Japan Sea tsunami, Bull. Earthq. Res. Inst., Univ. Tokyo, 61, 329-338, 1986 b.

Hatori, T., I. Aida, S. Sakashita, and T. Hibiya, Field survey of the Nankaido tsunamis inundating Yuasa and Hiro, Wakayama Prefecture, Bull. Earthq. Res. Inst., Univ. Tokyo, 58, 187-206, 1983.

Hokkaido Tsunami Survey Group, Tsunami devastates Japanese coastal region, Eos, 74, 417,432 (September 14), 1993.

Hwang, L.-S., H. L. Butler, and D. J. Divoky, Tsunami model: generation and open-sea characteristics, Bull. Seismol. Soc. Am., 62, 1579-1596, 1972.

Ide, S., F. Imamura, Y. Yoshida, and Ka. Abe, Source characteristics of the Nicaraguan tsunami earthquake of September 2, 1992, Geophys. Res. Lett., 20, 863-866, 1993.

Imamura, F. and C. Goto, Truncation error of numerical tsunami simulation by the finite difference method, Coastal Eng. Jpn., 31, 245-263, 1988.

Imamura, F. and N. Shuto, Analysis of the OBS data and numerical simulation for the 1990 Mariana earthquake tsunami, in Tsunamis in the World, ed. S. Tinti, pp. 95-105, Kluwer Academic.Publishers, Dordrecht, 1993.

Imamura, F., N. Shuto, and C. Goto, Study on numerical simulation of the transoceanic propagation of tsunamis-Part 2 Characteristics of tsunami propagating over the Pacific Ocean, Zisin (J. Seismol. Soc. Jpn.), 43, 389-402, 1990.

Imamura, F., N. Shuto, S. Ide, Y. Yoshida, and Ka. Abe, Estimate of the tsunami source of the 1992 Nicaraguan earthquake from tsunami data, Geophys. Res. Lett., 20, 1515-1518, 1993.

Iwasaki, S., On the generation mechanism of the low frequency $\mathrm{T}$ phase due to tsunamigenic earthquakes, in Proc. 2nd UJNR Tsunami Workshop, ed. A. M. Brennan and J. F. Lander, pp. 31-34, National Geophysical Data Center, Boulder, 1991.

Iwasaki, T. and A. Mano, Two-dimensional numerical computation of tsunami run-up in the Eulearian description, Proc. 26th Conf. Coastal Eng., JSCE, 70-74, 1979.

Izutani, Y. and T. Hirasawa, Use of strong motion duration for rapid evaluation of fault parameters, J. Phys. Earth, 35, 171-190, 1987.

Kajiura, K., The leading wave of a tsunami, Bull. Earthq. Res. Inst., Univ. Tokyo, 41, 535-571, 1963.

Kajiura, K., Tsunami source, energy and the directivity of wave radiation, Bull. Earthq. Res. Inst., Univ. Tokyo, 48, 835-869, 1970. 
Kajiura, K., Tsunami energy in relation to parameters of the earthquake fault model, Bull. Earthq. Res. Inst., Univ. Tokyo, 56, 415-440, 1981.

Kanamori, H., Mechanism of tsunami earthquakes, Phys. Earth Planet. Inter., 6, 346-359, 1972.

Kanamori, H. and M. Kikuchi, The 1992 Nicaragua earthquake: a slow tsunami earthquake associated with subducted sediments, Nature, 361, 714-716, 1993.

Kato, Y. and M. Kimura, Age and origin of so-called "Tsunami-ishi," Ishigaki Island, Okinawa Prefecture, J. Geol. Jpn., 8, 471-474, 1983.

Katsumata, M., The tsunami warning systems in Japan, Chigaku Zasshi, 96, 21-27, 1987.

Kawamata, S., F. Imamura, and N. Shuto, Numerical simulation of the 1883 Krakatau tsunami, Proc. Int. Assoc. Hydraulic Res., 24-31, 1993.

Kawamura, B. and T. Mogi, On the deformation of the sea bottom in some harbours in the Sanriku coast due to Chile tsunami, in Report on the Chilean Tsunami of May 24, 1960, as Observed along the Coast of Japan, ed. The Committee for Field Investigation of the Chilean Tsunami of 1960, pp. 57-66, Tokyo, 1961.

Latter, J. H., Tsunamis of volcanic origin: summary of causes, with particular reference to Krakatoa, 1883, Bull. Volcanol., 44, 467-490, 1981.

Matsutomi, H., Impulsive force of timbers drifted by tsunami, in Proc. 2nd UJNR Tsunami Workshop, ed. A. M. Brennan and J. F. Lander, pp. 51-61, National Geophysical Data Center, Boulder, 1990.

Meteorological Research Institute (MRI), Permanent ocean-bottom seismograph observation system, Tech. Rep. MRI, 4, 1-233, 1980.

Minoura, K. and S. Nakaya, Traces of tsunami preserved in inter-tidal lacustrine and marsh deposits: some examples from northeast Japan, J. Geol., 99, 265-287, 1991.

Miyabe, N., An investigation of the Sanriku tunami based on mareogram data, Bull. Earthq. Res. Inst., Univ. Tokyo, 1, Suppl., 112-126, 1934.

Murakami, K., The response of tide gauge to the tsunami, Tech. Note, Port Harbor Res. Inst., 470, 217-223, 1983.

Nagano, O., F. Imamura, and N. Shuto, A numerical model for far-field tsunamis and its application to predict damages done to aquaculture, Natural Hazards, 4, 235-255, 1991.

Nishimura, Y. and K. Satake, Numerical computations of tsunamis from the past and future eruptions of Komagatake volcano, Hokkaido, Japan, Tsunami '93, Proc. Int. Tsunami Symp., 573-583, 1993.

Nomanbhoy, N. and K. Satake, Generation mechanism of tsunamis from the 1883 Krakatau eruption, Geophys. Res. Lett., 22, 509-512, 1995.

Okada, M., Response of some tide-wells in Japan to tsunamis, Proc. Int. Tsunami Symp. 1985, 208-213, 1985.

Okada, M., Ocean bottom pressure gauge for tsunami warning system in Japan, in Proc. 2nd UJNR Tsunami Workshop, ed. A. M. Brennan and J. F. Lander, pp. 219-227, National Geophysical Data Center, Boulder, 1991.

Okal, E. A., Seismic parameters controlling far-field tsunami amplitudes: a review, Natural Hazards, 1, 67-96, 1988.

Rikitake, T. and I. Aida, Tsunami hazard probability in Japan, Bull. Seismol. Soc. Am., 78, 1268-1278, 1988.

Satake, K., Effects of bathymetry on tsunami propagation: application of ray tracing to tsunamis, Pageoph, 126, 27-36, 1988.

Satake, K., Inversion of tsunami waveforms for the estimation of heterogeneous fault motion of 
large submarine earthquakes: the 1968 Tokachi-oki and the 1983 Japan Sea earthquakes, $J$. Geophys. Res., 94, 5627-5636, 1989.

Satake, K., Depth distribution of coseismic slip along the Nankai trough, Japan, from joint inversion of geodetic and tsunami data, J. Geophys. Res., 98, 4553-4565, 1993.

Satake, K. and H. Kanamori, Abnormal tsunamis caused by the June 13, 1984, Torishima, Japan, earthquake, J. Geophys. Res., 96, 19933-19939, 1991.

Satake, K. and K. Shimazaki, Free oscillation of the Japan Sea excited by earthquakes. I. Observation and wave-theoretical approach, Geophys. J., 93, 451-456, 1988 a.

Satake, K. and K. Shimazaki, Free oscillation of the Japan Sea excited by earthquakes. II. Modal approach and synthetic tsunamis, Geophys. J., 93, 457-463, 1988 b.

Satake, K., M. Okada, and $\mathrm{Ku}$. Abe, Tide gauge response to tsunamis: measurements at 40 tide gauge stations in Japan, J. Mar. Res., 46, 557-571, 1988.

Satake, K., Y. Yoshida, and Ka. Abe, Tsunami from the Mariana earthquake of April 5, 1990: its abnormal propagation and implications to tsunami potential from outer-rise earthquakes, Geophys. Res. Lett., 19, 301-304, 1992.

Satake, K., J. Bourgeois, Ku. Abe, Ka. Abe, Y. Tsuji, F. Imamura, Y. lio, H. Katao, E. Noguera, and F. Estrada, Tsunami field survey of the 1992 Nicaragua earthquake, Eos, 74, 145, 156-157, 1993.

Sato, K., Y. Utsumi, K. Sato, Y. Koyama, A. Kumagai, H. Miyai, M. Komatsu, I. Saito, and K. Shirahata, Observation system for tide and tsunami-an example of system in Kesennuma city, Tsunami Eng. Tech. Rep., Tohoku Univ., 9, 1-17, 1992.

Sato, T., The Chilean tsunami and damages to aquaculture rafts in Mie Prefecture, Suisan-Zoshoku, 8, 193-202, 1960.

Sayama, J., N. Shuto, and C. Goto, Error induced by refraction in tsunami numerical simulation, Proc. 6th Congress, Asian and Pacific Regional Div., Int. Assoc. Hydraulic Res., 257-264, 1988.

Self, S. and M. R. Rampino, Comments on "A geophysical interpretation of the 1883 Krakatau eruption" by I. Yokoyama, J. Volcanol. Geotherm. Res., 13, 379-383, 1982.

Shuto, N., The effectiveness and limit of tsunami control forest, Coastal Eng. Jpn., 30, 143-153, $1987 \mathrm{a}$.

Shuto, N., Spread of oil and fire due to tsunamis, Proc. Int. Tsunami Symp. 1987, 188-204, 1987 b.

Shuto, N., C. Goto, and F. Imamura, Numerical simulation as a means of warning for near-field tsunami, Coastal Eng. Jpn., 33, 173-193, 1990.

Shuto, N., J. Sayama, and K. Fujima, Field survey of traces of the Great Sanriku tsunamis-Matsuzaki town in the city of Ofunato, Tsunami Eng. Tech. Rep., Tohoku Univ., 4, 101-113, 1987.

Shuto, N., T. Suzuki, K. Hasegawa, and K. Inagaki, A study of numerical techniques on the tsunami propagation and run up, Sci. Tsunami Hazards, 4, 111-124, 1986.

Tada, T., M. Tsukamoto, Y. Ueno, M. Kawashima, Y. Tsuji, T. Egawa, and Y. Yamazaki, Observations of seiches in Heda Bay, Shizuoka Prefecture, Bull. Earthq. Res. Inst., Univ. Tokyo, 66, 455-474, 1991.

Takahashi, R., On the seismic sea waves caused by deformation of the sea bottom, Bull. Earthq. Res. Inst., Univ. Tokyo, 20, 357-400, 1942.

Takahashi, T., F. Imamura, and N. Shuto, Numerical simulation of topography change due to tsunamis, Tsunami '93 Proc. Int. Tsunami Symp., 243-255, 1993.

Takeda, A. and Y. Tsuji, Discrimination of tsunami flooded area using satellite data, Proc. Int. Tsunami Symp. 1987, 35, 1987. 
Togashi, $H$. and $Y$. Hirayama, Hydraulic experiment on reappearance of the Ariake-kai tsunami in 1792, Tsunami '93 Proc. Int. Tsunami Symp., 741-754, 1993.

Tomizawa, M., F. Imamura, and N. Shuto, Hydraulic characteristics of a tsunami in the neighborhood of a sudden expansion, Proc. Jpn. Coastal Eng., 37, 131-134, 1990.

Tsuji, Y., Study on the earthquake and the tsunami of September 20, 1498, in Tsunamis: Their Science and Engineering, ed. K. Iida and T. Iwasaki, pp. 185-204, Terra Scientific Publ. Co., Tokyo, 1983.

Tsuji, Y., Victims of the 1707 and 1854 Tokai-Nankai earthquakes-tsunamis listed on necrologies of temples, Proc. Int. Tsunami Symp. 1987, 73-83, 1987.

Usami, T., Study of historical earthquakes in Japan (2), in Historical Seismograms and Earthquakes of the World, ed. W. H. K. Lee, H. Meyers, and K. Shimazaki, Academic Press, San Diego, 1988.

Ward, S., Relationships of tsunami generation and an earthquake source, J. Phys. Earth, 28, 441-474, 1980.

Ward, S. N., On tsunami nucleation. 1. A point source, J. Geophys. Res., 86, 7895-7900, 1981.

Ward, S. N., On tsunami nucleation. II. An instantaneous modulated line source, Phys. Earth Planet. Inter., 27, 273-285, 1982.

Watanabe, H., Catalog of Hazardous Tsunamis in Japan, Univ. of Tokyo Press, Tokyo, 206 pp., 1985.

Yamashita, T. and R. Sato, Generation of tsunami by a fault model, J. Phys. Earth, 22, 415-440, 1974.

Yeh, H., F. Imamura, C. Synolakis, Y. Tsuji, P. Liu, and S. Shi, The Flores Island Tsunamis, Eos, 74, 369, 371-373 (August 14), 1993.

Yokota, T. and M. Yamamoto, On the earthquake phenomena observation system (outline of the system), Q. J. Seismol., 52, 89-99, 1989.

Yokoyama, I., A geophysical interpretation of the 1883 Krakatau eruption, J. Volcanol. Geotherm. Res., 9, 359-378, 1981.

Yokoyama, I., A scenario of the 1883 Krakatau tsunami, J. Volcanol. Geotherm. Res., 34, 123-132, 1987.

Zama, S. and $\mathrm{H}$. Yoshihara, A system for rapid evaluation of tsunami potential of earthquake at a single station, Rep. Fire Res. Inst. Jpn., 64, 23-38, 1987.

Vol. 43, No. 3, 1995 